\title{
ANÁLISE DO COMPORTAMENTO ECOLÓGICO DE ESTUDANTES DE ADMINISTRAÇÃOO
}

\author{
*José Milton de Sousa Filho
}

miltonsousa@unifor.br

*Danielle Batista Coimbra

daniellecoimbra@unifor.br

*Rafael Fernandes de Mesquita

fernandesrafael@live.com

* Roger Augusto Luna

rog_luna@hotmail.com

*Universidade de Fortaleza - Fortaleza, CE / Brasil

http://dx.doi.org/10.1590/1413-2311.0192014.49413

Recebido em 09/05/2014

Aprovado em 07/07/2015

Disponibilizado em 01/08/2015

Avaliado pelo sistema "double blind review"

Revista Eletrônica de Administração

Editor: Luís Felipe Nascimento

ISSN 1413-2311 (versão "on line")

Editada pela Escola de Administração da Universidade Federal do Rio Grande do Sul.

Periodicidade: Quadrimestral

Sistema requerido: Adobe Acrobat Reader.

\section{RESUMO}

O comportamento ecológico, ou pró-ambiental, tanto de atividades quanto de aspectos de vida dos indivíduos e da sociedade em relação ao meio ambiente, relaciona-se diretamente à conscientização ambiental que, atualmente, tem apoio no ensino de graduação em disciplinas como educação ambiental, que buscam formar o profissional mais consciente de seus atos em relação ao ambiente natural. O presente estudo quantitativo e descritivo buscou entender os fatores que influenciam o Comportamento Ecológico de universitários do curso de Administração, usando como amostra alunos de Instituições de Ensino Superior públicas e privadas, do Estado do Piauí. Para coleta, utilizou-se a Escala de Comportamento Ecológico, validada por Pato e Tamayo (2006), aplicada a discentes do curso de Bacharelado em Administração, com amostras de 486 respondentes. Foram utilizadas análises descritivas e multivariadas para avaliar os dados. A partir da análise paralela e da análise fatorial exploratória encontrou-se seis fatores que, em seguida, foram utilizados como variáveis independentes na análise de regressão, cuja variável dependente era o Comportamento Ecológico. A análise de regressão apresentou modelo de altíssimo nível explicativo, com $\mathrm{R}^{2}=99,2 \%$, validando os fatores explicativos do comportamento ecológico que, neste estudo, diferem dos de Pato e Tamayo (2006), especialmente subdividindo "economia de água e energia" em um fator para cada recurso e, também, separando "ativismo-consumo" em "ativismo" e "ativismo-consumo". As contribuições teóricas do estudo residem na distinção 
José Milton de Sousa Filho, Danielle Batista Coimbra, Rafael Fernandes de Mesquita \& Roger Augusto Luna

de resultados, ainda que se utilizando respondentes similares, no caso, estudantes, o que pode ser devido a fatores culturais ou regionais.

Palavras-chave: Comportamento Ecológico; Comportamento Pró-Ambiental, Educação Ambiental; Comportamento Ecológico de Universitários.

\title{
ANALYSIS OF ECOLOGICAL BEHAVIOR OF BUSINESS STUDENTS
}

\begin{abstract}
The ecological, or pro-environmental behavior, both in activities and aspects of life of individuals and society in relation to the environment, are directly related to environmental conscientization that currently has support in undergraduate courses of environmental education, that aims to mold the professional most conscious of their actions in relation to natural environment. The current quantitative and descriptive study sought to understand the factors that influence the Ecological Behaviour of college students in public and private universities from the State of Piaui. It was used the Ecological Behavior Scale for collect data, validated by Pato and Tamayo (2006), applied to students of the Bachelor in Business Administration, with a sample of 486 respondents. Descriptive and multivariate analyzes were used to evaluate data. From the parallel analysis and exploratory factor analysis it was found six factors, which were then used as independent variables in the regression analysis, where the dependent variable was the Ecological Behavior. The results of this study differ from Pato and Tamayo (2006), especially subdividing "saving water and energy" by one factor to each resource, and also separating "activism-consumption" in "activism" and "activismconsumption". Regression analysis showed very high explanatory level model, with $\mathrm{R}^{2}=99.2 \%$, validating the explanatory factors of ecological behavior. The theoretical contributions of this study lie in the distinction of results even using similar respondents, in this case, students, which may be due to cultural or regional factors.
\end{abstract}

Keywords: Ecological Behavior; Environmental Behavior, Environmental Education; Undergraduate Ecological Behavior.

\section{ANÁLISIS DE COMPORTAMIENTO ECOLÓGICO DE ESTUDIANTES DE ADMINISTRACIÓN}

\section{RESUMEN}

El comportamiento ecológico o pro-ambiental, tanto en actividades como en aspectos de vida de los individuos y de la sociedad en relación con el medio ambiente, se relaciona directamente con la conscientización ambiental que, actualmente, tiene el apoyo en la enseñanza de graduación en las disciplinas de educación ambiental y otras transversales que buscan formar el profesional más conciente de sus actos con relación a su ambiencia natural. Este estudio cuantitativo y descriptivo buscó comprender los factores que influencian el Comportamiento Ecológico de académicos del curso de Administración, usando como muestra alumnos de IES públicas y privadas de la provincia de Piauí. Para la recolección se usó la Escala de Comportamiento Ecológico, validada por Pato y Tamayo (2006), aplicada a los estudiantes del curso de bachillerato en administración con muestra de 486 encuestados. Fueron usados análisis descriptivos y multivariados para evaluar los datos. Apartir del análisis

REAd | Porto Alegre - Edição 81 - Nº 2 - maio/agosto 2015 - p. 300-3019 


\section{ANÁLISE DO COMPORTAMENTO ECOLÓGICO DE ESTUDANTES DE ADMINISTRAÇÃO}

paralela y del análisis factorial explotatorio se encontró seis factores que se utilizaron entonces como variables independientes en el análisis de regresión, cuya variable dependiente era el Comportamineto Ecológico. El análisis de regresión presentó el modelo de altísimo nivel explicativo con $\mathrm{R}^{2}=99,2 \%$, validando los factores explicativos del comportamiento ecológico que, en este estúdio, difieren de la investigación de Pato y Tamayo (2006), especialmente la subdivisión de "ahorrar agua y energía" por uno factor para cada recurso y también separar "activismo-consumo" en "activismo" y "activismo-consumo". Las aportaciones teóricas de este estudio es la distinción de los resultados incluso utilizando los encuestados similares, en este caso, los estudiantes, lo que puede ser debido a factores culturales o regionales.

Palabras Clave: Comportamiento Ecológico; Comportamiento Pro-Ambiental, Educación Ambiental; Estudiantes de Gestión.

\section{INTRODUÇÃO}

Durante as últimas décadas, nas suas diversas áreas de aplicação, a educação ambiental tem dado origem a uma ampla gama de conceitos, desde o mais amplo até os mais pontuais (SAUVÉ, 1999). Dentre eles, o comportamento ecológico é visto como responsável tanto pela sua preocupação com a degradação do meio ambiente, quanto pela sua conservação (PATO; TAMAYO, 2006).

A análise de percepção ambiental torna-se um elemento importante para o planejamento, visto que uma das dificuldades para a proteção dos ambientes naturais consiste exatamente na existência de diferentes percepções dos valores e de sua importância entre os indivíduos de culturas diferentes ou grupos sócio-econômicos que desempenham distintas funções nesses ambientes (UNESCO, 1973).

O comportamento ecológico, tanto em atividades, quanto em aspectos de vida dos indivíduos e da sociedade em relação ao meio ambiente, relaciona-se diretamente à conscientização ambiental (BUTZKE et al., 2001). Tal conscientização, atualmente, tem apoio no ensino de graduação em disciplinas como educação ambiental, dentre outras desta área, que buscam formar o profissional mais consciente de seus atos em relação ao ambiente natural (MESQUITA et al., 2014, SILVA et al., 2013).

Em 1999 foi criada a Política Nacional de Educação Ambiental (PNEA), que obrigou mudanças nos diversos cursos de graduação no Brasil, já que tal política determina que a educação ambiental passe a ser tema obrigatório e transversal em todos os níveis educacionais. Dessa forma, todos os cursos de graduação, em diferentes áreas, necessitaram se adequar a PNEA, tal atividade também foi aplicada ao curso de Bacharelado em Administração.

O Bacharelado em Administração ocupa posição privilegiada, com o maior número de alunos matriculados do total de matrículas de curso de graduação no Brasil (INEP, 2012), justificando o destaque neste estudo. Além disso, é sabido o impacto que as empresas causam no meio ambiente, sendo muitas vezes alvo de processos judiciais, devido sua má conduta ambiental, e sendo responsabilizadas através de seus gestores. Os futuros gestores de empresas estão sendo formados hoje, nos cursos de Bacharelado em Administração. Desta forma, faz sentido entender o comportamento ecológico de tais alunos, já que no futuro estes serão responsáveis por empresas que podem causar impactos ambientais e prejudicar a sociedade.

Sabe-se que os temas educação ambiental e comportamento ecológico têm sido trabalhados no âmbito do Bacharelado em Administração, ao que se afirma ser uma condição

REAd | Porto Alegre - Edição 81 - № 2 - maio/agosto 2015 - p. 300-3019 
José Milton de Sousa Filho, Danielle Batista Coimbra, Rafael Fernandes de Mesquita \& Roger Augusto Luna

de isomorfismo na graduação nesta área (SILVA et al., 2013) e uma necessidade que se estende ao âmbito das empresas (CARVALHO; DIAS, 2013). Contudo, estudos que tratam das variáveis que explicam o comportamento ambiental ainda são pouco empreendidos. Entender melhor tais variáveis explicativas é relevante para teoria e prática, principalmente no que diz respeito ao suporte para planejamento de políticas e/ou programas que busquem ampliar o comportamento ecológico das pessoas.

Assim, dado o contexto e a relevância, o problema de pesquisa que norteou o presente trabalho foi: "Quais são as variáveis explicativas do comportamento ecológico de estudantes de Bacharelado em Administração?".

Para responder ao questionamento, tornou-se necessário conhecer a realidade brasileira em aspectos de educação ambiental, contextualizando seu arcabouço legal e o que os trabalhos acadêmicos dizem a seu respeito. Assim, o objetivo geral deste trabalho foi "Investigar as variáveis explicativas do comportamento ecológico de estudantes de Bacharelado em Administração". Em relação ao campo empírico, buscou-se analisar o comportamento ecológico de discentes do curso de bacharelado em administração de empresas na cidade de Teresina, capital do Piauí, usando a Escala de Comportamento Ecológico (ECE) desenvolvida e validada por Pato e Tamayo (2006).

A ECE foi desenvolvida a partir das medidas utilizadas por Karp (1996) e Kaiser (1998), medidas gerais para avaliação do comportamento ecológico, baseando-se especialmente nos trabalhos de Karp (1996). Pato e Tamayo (2006) aplicaram questionários com alunos de ensino médio e Bacharelado em Administração, com intervalos entre a apresentação dos resultados para discussão e reelaboração do instrumento de coleta de dados, resultando na escala utilizada, também, neste estudo.

O presente trabalho está estruturado da seguinte forma: apresenta-se o referencial teórico com uma seção inicial sobre a educação ambiental no contexto do ensino superior brasileiro, com foco na área de Administração, e outra seção sobre o comportamento ecológico. Em seguida são apresentados os aspectos metodológicos do estudo, os resultados e as principais conclusões.

\section{REFERENCIAL TEÓRICO}

\subsection{Educação Ambiental na Administração}

A educação foi diretamente afetada pelas turbulências que marcaram a virada do milênio. $\mathrm{O}$ desenvolvimento da ciência e da tecnologia permitiu a realização de mudanças nos processos produtivos, nas relações sociais e nas políticas de educação.

Nesse sentido, a educação, em todos os níveis, tem a importante e complicada missão de acompanhar os indivíduos na construção de sua história. Dowbor (1996) afirma que se está frente a uma mutação do próprio papel da educação no processo de reprodução social, uma vez que, anteriormente, destinava-se a disciplinar e mutilar o profissional para adequá-lo ao mundo do trabalho. Ainda na visão desse autor, é preciso que a educação esteja associada à formação dos valores humanos e à formação do cidadão e de sua visão crítica e criativa, pois o conhecimento, matéria-prima da educação, tornou-se o recurso estratégico do desenvolvimento moderno. Tais conceitos permanecem atuais no debate acadêmico sobre a educação e o desenvolvimento de ferramentas que acompanhem estas práticas diárias e transformadoras da realidade (MESQUITA et al., 2014).

Tudo indica que não estamos enfrentando apenas uma revolução tecnológica. Na realidade, o conjunto de transformações parece estar levando a uma sinergia da comunicação, informação e formação, criando uma realidade nova, que designaríamos algo pomposamente como 'espaço do conhecimento', mas que

REAd | Porto Alegre - Edição 81 - N 2 - maio/agosto 2015 - p. 300-3019 


\section{ANÁLISE DO COMPORTAMENTO ECOLÓGICO DE ESTUDANTES DE ADMINISTRAÇÃO}

representa exatamente isto. De certo modo, o processo reflete os primeiros passos do homo culturalis em contraposição ao homo economicus dos séculos XIX e XX, processo no qual entramos, como sempre, de forma desigual. (DOWBOR, 1996, p. 20).

Para participar e enfrentar tais mudanças cabe aos educadores a responsabilidade de estimular os educandos a assumirem a posição de sujeitos de sua própria formação, resgatando a sua cidadania, o que levaria a uma educação menos lecionadora ou instrutora e mais mobilizadora e ativa, características presentes no bojo da Educação Ambiental. Dessa forma, acredita-se que o trabalho com Educação Ambiental nos cursos de Administração pode fomentar uma percepção diferenciada e mais abrangente das questões ambientais, principalmente ao considerar-se que a realidade dos cursos de Administração advém de uma história de formação associada às necessidades do mercado de trabalho (CARVALHO; DIAS, 2013; SILVA et al., 2013).

A origem dessa percepção reside numa abordagem econômica da educação ainda muito presente nessa área de formação, e, assim como as pessoas são tratadas como recurso ou capital, os elementos que compõem o meio ambiente se enquadram na mesma perspectiva. Em tal abordagem, as pessoas podem ser produtivas ou não para as organizações, e uma série de estudos foi desenvolvida nesse sentido. Mesmo as abordagens humanísticas que sucederam a Escola Clássica da Administração (Taylorismo - Fordismo) têm, em seu escopo, a preocupação com a produtividade, representando a mentalidade e filosofia hegemônicas da Administração da primeira metade do século XX.

Para tal perspectiva as pessoas eram vistas como coadjuvantes, que tinham de se ajustar para garantir o sucesso dos processos operacionais e dos resultados das organizações - leia-se "lucro" - e, apesar de o discurso atual apresentar conotações diferentes, não se crê que tenha havido uma mudança real do sentido que as pessoas assumem para as organizações, principalmente ao considerar-se a realidade brasileira.

Entende-se que a mudança foi apenas na denominação, ou seja: o que antes era mão de obra, agora é capital intelectual. É fato que uma série de elementos foi incorporada às organizações no intuito de beneficiar os colaboradores. Incentivos e ferramentas que fomentaram as suas autorrealizações foram incorporados aos processos de Gestão de Pessoas. No entanto, o foco continuou a ser a produtividade: o resultado gerado pelo ex-funcionário e agora colaborador.

Foi a economia neoclássica que fundamentou, durante muito tempo, esse modelo, e as instituições de educação acompanharam as exigências do mercado, já que o sentido da educação estava na "formação para o emprego". Isso fomentou uma concepção conservadora de ensino na área, na qual os alunos literalmente aprendem técnicas e processos com base em padrões já existentes, para que, assim, estejam aptos a assumir funções específicas dentro de uma organização.

Mas esse não foi o único caminho. $\mathrm{Na}$ área da Administração sempre existiram visões pautadas numa percepção crítica que buscaram orientar a implementação de abordagens diferenciadas. A Teoria Crítica aborda, basicamente, a resistência à dominação que determinados grupos exercem sobre outros, dentro ou fora das organizações. Nesse sentido, tem como finalidade libertar os "oprimidos" da dominação por meio do esclarecimento e da autorreflexão. Tem como influência os escritos de Marx, Freud e Nietzsche e deve à Escola de Frankfurt boa parte de seu arcabouço conceitual.

Guerreiro Ramos é outro nome de destaque nessa linha de trabalho com enfoque diferenciado para a Administração. Foi professor da EBAP (Escola Brasileira de Administração Pública de Empresas), tendo proferido a primeira aula da Escola em 1952. Professor de Sociologia no curso de Administração, um de seus primeiros desafios foi REAd | Porto Alegre - Edição 81 - N 2 - maio/agosto 2015 - p. 300-3019 
José Milton de Sousa Filho, Danielle Batista Coimbra, Rafael Fernandes de Mesquita \& Roger Augusto Luna

preocupar-se com a produção de literatura administrativa fundamentada na experiência brasileira, vencida a etapa da tradução de clássicos em língua inglesa. Dessa forma, foi publicado o livro Administração e Estratégia do Desenvolvimento (sua primeira edição saiu em 1966), reeditado em 1983 pela FGV (Fundação Getúlio Vargas) com outro título Administração e Contexto Brasileiro. Esse livro apresentava críticas à literatura administrativa convencional, produzida basicamente no âmbito da teoria e da prática norteamericana, que, como visto, influenciou de forma bastante significativa o ensino dessa área no Brasil.

Guerreiro Ramos nunca dissociou a Administração do âmbito das Ciências Sociais, ou melhor, do fenômeno social. A preocupação manifestada por ele com as organizações e como-homem-que-trabalha-nas-organizações sempre esteve ligada ao fato social, com o tratamento de temas como: por que as organizações (produtivas) são como são e que consequências trazem para as pessoas, individualmente ou em grupo, produtivos ou não? Não se vai encontrar na sua obra qualquer preocupação com atividades adjetivas, ligadas a técnicas administrativas ou a métodos de quaisquer tipos, salvo se reinterpretados em função de realidades e necessidades objetivas, as quais, muitas vezes, ignoram ou desprezam os manuais de procedimentos.

O desafio para a formação do Administrador é preparar um profissional que tenha a capacidade de atuar como "agente transformador, se ajustando com rapidez aos avanços da ciência e da tecnologia no estabelecimento de uma nova ordem" (GUERRA, 2001, p. 6).

Assim, acredita-se que o arcabouço conceitual desenvolvido e defendido por Guerreiro Ramos a partir das referências da Teoria Crítica para a Administração vai ao encontro da essência da Educação Ambiental e se constitui como uma nova possibilidade de ensino para a área, principalmente considerando-se a premente necessidade de implementação de uma abordagem de trabalho que invista na formação de cidadãos e cidadãs conscientes e críticos, capazes de refletir sobre o contexto em que estão inseridos e problematizar situações de forma diferenciada, questionando tendências hegemônicas e totalitárias e trazendo soluções criativas e inclusivas que contribuam para o bem-estar da sociedade.

Nesse sentido, o trabalho com a Educação Ambiental nos cursos superiores de Administração precisa ser ampliado, superando as limitações relacionadas às demandas do mercado nesse novo momento em que as questões ambientais assumem papel fundamental em todos os âmbitos e segmentos. A sistematização do ensino da temática ambiental nos cursos de Administração tem crescido no âmbito acadêmico, mas, apesar disso, os resultados do trabalho ainda são incipientes (BARBIERI, 2004; KRUGLIANSKAS, 1993; SALGADO, 2002).

Para Gonçalves-Dias et al. (2009) houve um crescimento da preocupação com a incorporação de ensino ambiental nos cursos de administração, no entanto, tal preocupação ainda não se reverteu em mudanças representativas. $O$ aumento da quantidade de cursos superiores na área não solucionou os desafios presentes para a inserção da temática ambiental.

A Resolução de $n^{\circ} 1$, de 02/02/2004, que institui as diretrizes curriculares nacionais nos cursos de graduação em Administração, não discute explicitamente a Educação Ambiental, deixando-a subentendida, porém, apoiada pela Política Nacional de Educação Ambiental. No entanto, a ausência de orientações específicas contribui para que o processo de institucionalização da temática nas instituições que trabalham com cursos de graduação em Administração não fuja à regra do que acontece no ensino superior de maneira geral, variando conforme o contexto e as características culturais das instituições de ensino.

Um forte indicador das limitações do trabalho com a questão ambiental nos cursos de administração é a pouca produção acadêmica referente à área. Jabbour, Santos e Barbieri (2008), através de um levantamento de toda a produção científica entre os anos 1996 e 2005, 


\section{ANÁLISE DO COMPORTAMENTO ECOLÓGICO DE ESTUDANTES DE ADMINISTRAÇÃO}

observaram que apenas $2,3 \%$ do total de trabalhos em administração no Brasil são na área da gestão ambiental.

Não apenas a baixa quantidade de trabalhos publicados, mas a falta de diversidade autoral também é um dado preocupante, pois, além de se observar uma concentração da massa crítica em gestão ambiental em determinados centros de ensino e pesquisa, grande parte da produção é relativa a um restrito número de pesquisadores.

Uma dado relevante é que apenas cinco instituições de ensino e pesquisa concentram quase $60 \%$ da produção levantada, que se mostra, no todo ou em parte, atrelada a quatro pesquisadores que, tomados em conjunto, correspondem a $32 \%$ das pesquisas em gestão ambiental empresarial dos periódicos examinados (JABBOUR; SANTOS; BARBIERI, 2008, p. 706).

De acordo com Thomaz (2006), a implantação da Educação Ambiental está associada muito mais a iniciativas individuais de professores. Para Barbieri (2004), a maioria dos programas de cursos superiores trata a Educação Ambiental de forma isolada, restringindo seu escopo a atividades pontuais, como o Dia do Meio Ambiente ou programas de Coleta Seletiva de Lixo. O que retrata uma concepção conservadora e limitada da Educação Ambiental ainda predominando nessas instituições. Pode também ser considerada pequena a oferta de disciplinas associadas ao Meio Ambiente ou à Educação Ambiental nos cursos de graduação.

Estudos como o de Ferreira e Ferreira (2008) apontam que a presença da educação ambiental nos cursos de graduação em administração está concentrada em uma disciplina, chamada normalmente de Gestão Ambiental. Não obstante, $50 \%$ dos cursos analisados na pesquisa não possuem nem mesmo esta disciplina em sua grade curricular, apresentando um vácuo no que diz respeito à educação ambiental em seus programas de ensino.

Se mesmo com a presença da disciplina no currículo dos cursos as limitações na formação são significativas, a ausência total é ainda mais preocupante para este tipo de formação, já que é recomendado que "a temática deve ser contemplada em todas as grades curriculares do referido curso" (FERREIRA; FERREIRA, 2008, p. 14).

É fato ser uma vantagem que algumas instituições já tenham trabalhado os currículos inserindo essas temáticas na graduação; no entanto, é importante avaliar até que ponto existe uma adequação do trabalho a partir, inclusive, dos princípios e objetivos norteadores para a Educação Ambiental, a fim de que se tenham resultados condizentes com as diretrizes da Política Nacional de Educação Ambiental. O que se observa nos cursos de Administração é a predominância de uma Educação Ambiental orientada para a gestão. Em outras palavras, como as diretrizes curriculares não estabelecem a implantação da Educação Ambiental enquanto disciplina, para valorizar o tema, as disciplinas são concebidas com foco na gestão ou na responsabilidade social empresarial.

A "Educação" ambiental pressupõe uma abrangência maior nas questões que discute e nos objetivos a que se propõe. Em Tbilisi (1977) ficou estabelecido que o processo educativo deveria ser orientado para a resolução dos problemas concretos do meio ambiente, por intermédio de enfoques interdisciplinares e da participação ativa e responsável de cada indivíduo e da coletividade, o que se aplica a qualquer área do conhecimento.

Apesar de o termo "gestão" compreender elementos que envolvem planejamento, organização, implementação e controle de ações sob a perspectiva ambiental, ele não é suficiente para alcançar os objetivos a que se propõe a Educação Ambiental que está comprometida com a transformação, promoção da consciência e envolvimento da sociedade a partir de um enfoque global sustentado em base interdisciplinar, sendo também ferramenta para a renovação permanente dos processos educativos.

REAd | Porto Alegre - Edição 81 - Nº 2 - maio/agosto 2015 - p. 300-3019 
José Milton de Sousa Filho, Danielle Batista Coimbra, Rafael Fernandes de Mesquita \& Roger Augusto Luna

Para Coimbra (2011), apesar de, "em tese", preparar parcialmente os futuros administradores para atuar na "Gestão Ambiental" nas empresas, as limitações no entendimento sobre as questões ambientais acabam sendo maquiadas, criando discursos diferenciados, mas práticas que seguem os mesmos padrões que marcaram a origem do ensino na área e não produzem resultados significativos para a sociedade. Seguindo esse padrão, as ações dos profissionais em formação continuarão tendo uma orientação meramente pragmática, com foco no controle dos problemas ambientais e de gerenciamento de custos para as organizações. Salienta-se, mais uma vez, que o trabalho com a Educação Ambiental nos cursos de Administração precisa partir de uma perspectiva crítica, com foco não apenas no ambiente empresarial, mas no ambiente social.

As dificuldades de trazer para a Administração as questões ambientais podem ser associadas às necessidades de mudança de cultura e comportamentos, principalmente no ambiente empresarial, onde a visão pragmática e mercantilista constitui a base de todas as relações. Nesse contexto, para os estudantes da área, a Educação Ambiental é um paradoxo, já que eles não conseguem perceber de que forma sua implementação trará benefícios aos "negócios" dos quais farão parte, solidificando a percepção de que investir em meio ambiente representa apenas custo para a empresa.

O despertar de uma mentalidade provocadora de mudanças na educação voltada para as questões ambientais dentro dos ambientes organizacionais demanda uma expertise diferenciada, e, mais do que isso, uma consciência plena do papel que cada um assume, inicialmente como cidadão e, depois, como gestor.

Loures (2009) reforça a premissa da necessidade que os administradores tenham um bom julgamento nos assuntos que dizem respeito ao meio ambiente, mas isso só será possível através da introdução de aperfeiçoamentos substanciais nos cursos de administração. Apenas um trabalho pautado na agregação, em uma visão sistêmica, propiciará experiências de aprendizado diferenciadas e contextualizadas, que contribuam com a formação desse profissional com perfil diferenciado. As questões associadas à área de meio ambiente precisam ser apresentadas e discutidas com os alunos, trazendo à tona o papel que cada um deve assumir como profissional e como cidadão.

Considerando-se o encontro entre educação e meio ambiente, toda a história da Educação Ambiental e suas linhas de trabalho e a implementação do tema na área de Administração, reitera-se que o assunto é de fundamental importância para que se possa caminhar em outro sentido, tendo-se a preocupação de formar não apenas mão de obra, mas de alcançar a finalidade básica da Educação Ambiental, qual seja: promover as transformações necessárias e garantir a sustentabilidade dos recursos que asseguram não apenas a qualidade de vida da sociedade, mas a continuidade da vida neste planeta.

\subsection{Comportamento Ecológico}

Em um dado momento da história a qualidade de vida passou a ser avaliada fundamentalmente pela capacidade de consumo, razão pela qual a maioria das pessoas não media esforços para suprir seus "desejos". Esse modelo de sociedade, pautado na procura incessante do "material", vinha exaurindo os recursos naturais do planeta sem, no entanto, melhorar as condições de vida de grande parte da população da Terra. Os grandes desastres ambientais decorrentes deste modelo foram importantes para um despertar comum em relação aos problemas ambientais (LINS et al., 2011; BEURON et al., 2012; SIMÕES et al., 2012).

Butzke et al. (2001) consideram que a consciência ambiental é um conjunto de conceitos adquiridos pelas pessoas através de informações percebidas no ambiente, influenciando assim o comportamento ecológico. Este comportamento está associado a um novo paradigma e às alternativas de vida que decorrem da consciência ambiental e de REAd | Porto Alegre - Edição 81 - Nº 2 - maio/agosto 2015 - p. 300-3019 


\section{ANÁLISE DO COMPORTAMENTO ECOLÓGICO DE ESTUDANTES DE ADMINISTRAÇÃO}

repensar atitudes e valores que geram ações concretas pró-ambientais (LINS et al., 2011). O distanciamento entre homem e natureza ainda predomina, mas existem sinais positivos de redução desta distância.

É fato que o interesse pelo comportamento ambiental dos indivíduos vem crescendo nas últimas décadas, o descobrimento de características pessoais, hábitos e culturas que estão envolvidos neste processo comportamental, que tanto influenciam tomadas de decisões em relação ao meio ambiente (CORRAL-VERDUGO; PINHEIRO, 1999). Segundo Hines et al. (1987) existe uma maior tendência de pessoas cuidarem de seu entorno, especialmente quando elas possuem maior conhecimento, pois são responsáveis e desenvolvem crenças próambientais.

O estudo realizado por Carvalho (1998) demonstra que crianças entre 2-3 anos, quando estão inseridas em ambientes que colaboram com o aprendizado ecológico, são estimuladas a desenvolverem o raciocínio e a participação ativa nas atividades ambientais propostas. Com Corral-Verdugo e Pinheiro (1999) pode-se desenhar um quadro mais realista sobre o comportamento ecológico a partir do momento em que se reconhece e conhece a cultura do grupo, além também de possibilitar o planejamento de estratégias de intervenção em problemas de degradação ambiental. Lins et al. (2011) esclarecem que os comportamentos humanos são mutáveis, mesmo aqueles ditos ambientalmente adequados, por isso uma necessidade de estímulo constante a direcionar estas mudanças à realidade contemporânea.

Hines et al. (1987) concordam que as variáveis demográficas, isto é, a região em que o indivíduo está inserido, não influenciam em seu comportamento ecológico, mas sim o ambiente em que estão situados, exerce uma influência positiva. Barker (1965) acredita que os fenômenos ambientais e o comportamento não estão estabelecidos ainda a ponto de separar o indivíduo do ambiente onde ele está inserido. Mas em ambientes variados e em constante mudança, estes fenômenos ambientais se tornarão grandes fontes de pesquisas (BARKER, 1965).

O comportamento ecológico - assim como o comportamento humano de modo geral então, é mutável e pode sofrer alterações que conduzam as ações individuais e coletivas à aproximação de interesses entre a preservação ambiental e o progresso da qualidade de vida humana.

\section{METODOLOGIA}

\subsection{Delineamento da pesquisa}

O delineamento da pesquisa tem um papel importante, pois delimita o escopo, as técnicas e os métodos que serão utilizadas a fim de se obter as respostas necessárias referentes ao problema de pesquisa. Desta forma, a pesquisa realizada teve caráter quantitativo e descritivo. A abordagem quantitativa é frequentemente utilizada em estudos descritivos que buscam entender o comportamento entre variáveis e construtos.

A pesquisa seguiu os seguintes passos: (a) a revisão da literatura, (b) definição da escala a ser utilizada, (c) coleta de dados, (d) análise descritiva dos dados, (e) análise de confiabilidade da escala e (f) análise multivariada dos dados. A seguir serão explicados os procedimentos de coleta de dados.

\subsection{Amostra e coleta de dados}

O presente trabalho foi desenvolvido com estudantes universitários do curso de Bacharelado em Administração de Empresas de Instituições de Ensino Superior - IES 
José Milton de Sousa Filho, Danielle Batista Coimbra, Rafael Fernandes de Mesquita \& Roger Augusto Luna

públicas e privadas, na cidade de Teresina - PI. Conforme combinado com as IES, suas identidades serão mantidas em sigilo. A pesquisa foi realizada com 662 indivíduos respondentes, dos quais 486 questionários foram válidos, pois os demais não estavam preenchidos por completo e, por isso, foram descartados. Utilizou-se como técnica de pesquisa: a aplicação de questionários em vários dias dos meses de Outubro e Novembro de 2013.

$\mathrm{O}$ instrumento foi elaborado com 10 questões que buscavam identificar o perfil sociodemográfico do público, e outras 29 afirmações que fazem parte da Escala de Comportamento Ecológico (ECE) (PATO; TAMAYO, 2006), mensuradas por uma escala tipo Likert, de cinco pontos, variando de 1 (nunca) a 5 (sempre). Depois de coletados os questionários, estes foram tabulados e analisados com apoio do software estatístico IBM SPSS Statistics v. 20.0.

Os questionários foram aplicados coletivamente, durante o horário das aulas com permissão das IES e dos professores que permaneceram em sala no momento da aplicação. $\mathrm{O}$ pré-teste foi aplicado com uma amostra de 15 alunos cujas respostas não participaram dos resultados das análises. Este teste teve por finalidade refinar o instrumento de coleta, verificar a aplicabilidade e o tempo de resposta. Durante a aplicação do questionário final, os professores explicavam brevemente os objetivos do estudo, entregavam os questionários aos alunos que demonstravam interesse em participar da pesquisa e, depois de respondidos, recebiam o formulário de volta. Cabe evidenciar que os discentes demonstravam interesse em participar do estudo como respondentes e outros professores, que não os pesquisadores autores deste trabalho, também se apresentaram dispostos a apoiar a operacionalização da pesquisa. Os alunos foram voluntários e não houve identificação pessoal de suas respostas. Permaneceram, assim, anônimos os alunos e as instituições participantes.

\subsection{Análise dos dados}

Foram utilizadas análises descritivas e multivariadas para avaliar os dados. Inicialmente, para verificar a confiabilidade da escala empregada foi executado e teste do Alfa de Cronbach. Em seguida, no intuito de reduzir a quantidade de variáveis do estudo, foram efetuados procedimentos de Análise Fatorial Exploratória (AFE), e para definir o melhor número de fatores foi executada a Análise Paralela (Parallel Analysis) (O'CONNOR, 2000; LEDESMA; VALERO-MORA, 2007). Após tais procedimentos, os fatores encontrados foram utilizados como variáveis independentes na Análise de Regressão Múltipla, no intuito de entender como estas influenciam a variável dependente Comportamento Ecológico, foco principal desta pesquisa. A seguir serão mostrados os resultados das análises.

\section{RESULTADOS}

\subsection{Análise descritiva}

Participaram do estudo 486 estudantes de graduação em Administração, sendo 389 (80\%) de IES privadas, e 97 (20\%) de IES públicas. Desses estudantes, 233 (47,9\%) foram homens, e $253(52,1 \%)$ mulheres, com média de idade de 27 anos e distribuídos em relação ao semestre do curso conforme mostra a Tabela 1. Excetuando-se a baixa quantidade de respondentes do quinto semestre, pode-se observar nos demais um equilíbrio no número de estudantes pesquisados. 

ADMINISTRAÇÃO

Tabela 1 - Distribuição de respondentes por semestre

\begin{tabular}{lccc}
\hline Semestre & Frequência & Percentual & Percentual Acumulado \\
\hline Primeiro & 75 & 15,4 & 15,4 \\
\hline Segundo & 50 & 10,3 & 25,7 \\
\hline Terceiro & 74 & 15,2 & 40,9 \\
\hline Quarto & 76 & 15,6 & 56,6 \\
\hline Quinto & 18 & 3,7 & 60,3 \\
\hline Sexto & 53 & 10,9 & 71,2 \\
\hline Sétimo & 84 & 17,3 & 88,5 \\
\hline Oitavo & 56 & 11,5 & 100,0 \\
\hline Total & 486 & 100,0 & \\
\hline \multicolumn{5}{c}{ Fonte: Elaborada pelos autores com dados da pesquisa (2014). }
\end{tabular}

Apesar de mencionado neste trabalho que a educação ambiental, assim como o tema transversal do comportamento ecológico, tem sido discutida no âmbito do curso de Bacharelado em Administração em formato de disciplinas específicas da grade curricular, as instituições de ensino nas quais os alunos foram sujeitos investigados não apresentavam padronização de oferta da disciplina nos mesmos períodos letivos. A partir dessa realidade, não foi possível analisar neste estudo quais eram as variações percebidas de impacto e eficácia do conteúdo ministrado em comparação entre os períodos anteriores e posteriores da matéria.

A seguir estão descritos os procedimentos empreendidos na Análise Fatorial no intuito de reduzir a quantidade de variáveis para posterior Análise de Regressão.

\subsection{Análise fatorial}

Inicialmente foi verificada a confiabilidade da escala a partir do Alfa de Cronbach. Para a escala com 29 itens utilizada (Escala de Comportamento Ecológico - ECE, de Pato e Tamayo (2006) foi obtido um Alfa de 0,850 .

Após tal verificação, foi utilizada a Análise Paralela (Parallel Analysis) (O'CONNOR, 2000) para estimar a quantidade de fatores a serem utilizados. A análise paralela é uma técnica de simulação de Monte Carlo que auxilia pesquisadores na determinação do número de fatores, quando utilizado o método de Análise de Componentes Principais (Principal Component Analysis) na Análise Fatorial Exploratória (AFE) (O'CONNOR, 2000; LEDESMA; VALERO-MORA, 2007). A análise paralela fornece uma alternativa superior as outras técnicas que são comumente utilizados para o mesmo fim, tais como o Scree test ou a regra do Kaiser eigenvalue (autovalor) superior a um (LEDESMA; VALERO-MORA, 2007). Para efetuar a análise paralela foi utilizado o algoritmo de O'Conor (2000) como sintaxe no IBM SPSS Statistics v. 20.0.

Após executar a análise paralela, o resultado indicou seis fatores como melhor alternativa. Em seguida procedeu-se a AFE utilizando-se o método de análise dos componentes principais e rotação varimax. A AFE apresentou um índice Kaiser-Meyer-Olkin (KMO), medida de adequação da amostra, igual a 0,841, considerado adequado (HAIR et al., 2009), e teste de esferacidade de Bartlett estatisticamente significante (significativo ao nível de 0,000, com 406 graus de liberdade, e qui-quadrado de 3970,559).

A solução fatorial dos seis fatores encontrados (explicando $51 \%$ da variância total), as cargas das variáveis nos fatores, as comunalidades e os percentuais de variância explicada estão apresentadas no Apêndice A. Ao comparar com o trabalho de Pato e Tamayo (2006), que tiveram uma solução fatorial com 4 fatores que explicavam $35 \%$ da variância total, considera-se que o modelo do presente trabalho está adequado, pois que encontrou-se seis fatores que explicam $51 \%$ da variância total.

REAd | Porto Alegre - Edição 81 - N 2 - maio/agosto 2015 - p. 300-3019 
José Milton de Sousa Filho, Danielle Batista Coimbra, Rafael Fernandes de Mesquita \& Roger Augusto Luna

Conforme recomendação de Hair et al. (2009), as cargas fatoriais aceitas foram aquelas acima de 0,600. A partir disso, pode-se observar que as variáveis V3 (Faço trabalho voluntário para um grupo ambiental), V4 (Evito comprar produtos que são feitos de plástico), V8 (Compro comida sem me preocupar se têm conservantes ou agrotóxicos), V10 (Quando estou em casa, deixo as luzes acesas em ambientes que não são usados), V11 (Enquanto escovo os dentes, deixo a torneira aberta), V12 (Evito desperdício de energia), V17 (Apago a luz quando saio de ambientes vazios), V18 (Quando abro a geladeira já sei o que vou pegar, evitando ficar com a porta aberta muito tempo, para não gastar energia), V19 (Evito desperdício dos recursos naturais), V21 (Evito ligar vários aparelhos elétricos ao mesmo tempo nos horários de maior consumo de energia), V24 (Quando não encontro lixeira por perto, jogo latas vazias no chão) e V29 (Jogo todo tipo de lixo em qualquer lixeira) não obtiveram carga fatorial acima de 0,600 para nenhum dos fatores, sendo posteriormente excluídas das análises.

A partir da análise de cada fator, procedeu-se com a nomenclatura. Para o fator 1 (F1) que carregou as variáveis V13, V14 e V15 deu-se o nome de "Economia de Água". O fator 2 (F2) que carregou as variáveis V22, V23, V25 e V26 nomeou-se como "Limpeza Urbana". Já o fator 3 (F3) recebeu o nome de "Ativismo-Consumo", pois contou com as variáveis V5, V6, V7 e V9. O fator 4 (F4) carregou as variáveis V16 e V20 e recebeu o nome de "Economia de Energia". O fator 5 (F5) recebeu o nome de "Reciclagem", pois carregou as variáveis V27 e V28 que tratam desse tema. Por fim, o fator 6 (F6) carregou as variáveis V1 e V2, e por isso foi nomeado como "Ativismo", já que tais variáveis tratam dessa temática.

\subsection{Análise de regressão}

Após reduzir as 29 variáveis da Escala de Comportamento Ecológico (PATO; TAMAYO, 2006) utilizada nesta pesquisa para seis variáveis (fatores) procedeu-se a Análise de Regressão. A variável dependente da equação de regressão foi o Comportamento Ecológico, calculada a partir do somatório das respostas de cada estudante pesquisado, dividindo-se o total pela quantidade de variáveis. Com isso, obteve-se uma média simples das respostas, o que representa a intensidade do comportamento de cada respondente em favor (ou contra) o meio ambiente. Como variáveis independentes foram utilizados os fatores resultantes da AFE. Assim, a equação de regressão utilizada foi a seguinte:

$$
C E=\beta_{0}+\beta_{1} F 1+\beta_{2} F 2+\beta_{3} F 3+\beta_{4} F 4+\beta_{5} F 5+\beta_{6} F 6+\varepsilon
$$

(Modelo)

Onde:

$\mathrm{CE}=$ Indicador de comportamento ecológico

$\mathrm{F} 1$ = Economia de água

F2 = Limpeza urbana

F3 = Ativismo-consumismo

F4 = Economia de energia

F5 = Reciclagem

F6 = Ativismo

Em seguida, conduziu-se a análise de regressão múltipla. O modelo de regressão apresentou um coeficiente de determinação $\left(\mathrm{R}^{2}\right)$ de $99,6 \%(0,996)$ e um coeficiente de determinação ajustado ( $\mathrm{R}^{2}$ Ajustado) de 99,2\% (0,992). Desta forma, pode-se afirmar que as variáveis independentes utilizadas explicam $99,2 \%$ da variação da variável dependente, já que 


\section{ANÁLISE DO COMPORTAMENTO ECOLÓGICO DE ESTUDANTES DE ADMINISTRAÇÃO}

o modelo como um todo é significante $(0,000)$. As tabelas referentes ao modelo de regressão, bem como os testes de seus pressupostos, podem ser vistos no Apêndice B.

A partir dos resultados da análise de regressão, observa-se que todas as variáveis apresentaram significância estatística, assim, estas constituíram a seguinte equação de regressão:

$$
\mathrm{CE}=3,320+0,271 \mathrm{~F} 1+0,265 \mathrm{~F} 2+0,239 \mathrm{~F} 3+0,212 \mathrm{~F} 4+0,181 \mathrm{~F} 4+0,122 \mathrm{~F} 6
$$

A seguir tais resultados serão discutidos.

\section{DISCUSSÃO E CONCLUSÕES}

O presente estudo quantitativo, de caráter descritivo, buscou responder a seguinte pergunta de pesquisa: "Quais são as variáveis explicativas do comportamento ecológico dos estudantes do curso de administração?". Para entender o comportamento ecológico de estudantes universitários do curso de Administração, coletou-se os dados junto aos alunos de IES públicas e privadas no Estado do Piauí, e para isso, optou-se pela utilização da Escala de Comportamento Ecológico validada por Pato e Tamayo (2006). A partir de análises descritivas e multivariadas, encontrou-se seis fatores que foram utilizados como variáveis independentes na análise de regressão, cuja variável dependente era o Comportamento Ecológico dos estudantes.

Os resultados da AFE demonstraram resultados similares aos de Pato e Tamayo (2006), inclusive os fatores nomeados na presente pesquisa foram inspirados no trabalho desses autores. As diferenças ficaram por conta, principalmente, da quantidade de fatores, que em Pato e Tamayo (2006) foram quatro e neste trabalho foram seis. Um dos fatores encontrados pelos autores foi "Economia de Água e Energia", que neste trabalho carregou separadamente, pois F1 foi designado como "Economia de Água" e F4 foi nomeado como "Economia de Energia".

A outra diferença no que diz respeito aos fatores está em F3 "Ativismo-Consumo" e F6 "Ativismo". Pato e Tamayo (2006) encontraram apenas o fator "Ativismo-Consumo", pois variáveis relacionadas exclusivamente ao ativismo não carregaram sozinhas em um único fator, conforme ocorreu no presente trabalho.

Tais diferenças entre o trabalho de Pato e Tamayo (2006) e este, configuram uma contribuição teórica relevante, pois mostram a distinção de resultados mesmo utilizando-se respondentes similares, no caso, estudantes (Pato e Tamayo, 2006, utilizaram universitários de diversos cursos e também alunos de ensino médio). Sugere-se que tais diferenças podem ser devido aos fatores culturais, já que o presente estudo foi desenvolvido com respondentes do Nordeste, e Pato e Tamayo (2006) fizeram seu estudo com estudantes do Centro-Oeste, no Distrito Federal. Esse argumento contrapõe-se à Hines et al. (1987), quando afirmam que a região que o indivíduo está inserido não influencia em seu comportamento ecológico.

A contribuição teórica também diz respeito ao nível de explicação do modelo, pois a AFE revelou uma solução com seis fatores que explicam $51 \%$ da variância, enquanto a solução de Pato e Tamayo (2006) com quatro fatores explicou 35\% da variância. Desta forma, amplia-se o poder de explicação com os seis fatores sugeridos na presente pesquisa.

Tratando da análise de regressão, os fatores utilizados como variáveis independentes demonstraram um altíssimo poder de explicação da variável dependente Comportamento Ecológico, já que $99,2 \%$ da variação da dependente foi explicada pelas variáveis independentes. Tal nível de explicação demonstra que tanto os fatores utilizados como variáveis, quanto as variáveis originais (que geraram os fatores) estão na direção correta para 
José Milton de Sousa Filho, Danielle Batista Coimbra, Rafael Fernandes de Mesquita \& Roger Augusto Luna

mensurar o fenômeno do comportamento ecológico. Ainda, caso instituições ou governos queiram implementar algum programa com foco em aumentar o nível de comportamento ecológico das pessoas, podem se orientar pelas variáveis da ECE, propostas por Pato e Tamayo (2006), e utilizadas neste estudo.

Vale ainda ressaltar que apesar do alto nível de explicação do modelo de regressão, os coeficientes das variáveis foram baixos (todos abaixo de 1,0), o que suscita questões referentes ao poder de influência de cada variável. A partir da análise dos coeficientes, que variaram entre 0,122 (Ativismo) e 0,271 (Economia de Água), pode-se afirmar que a influência das variáveis independentes é muito baixa em relação à variável dependente Comportamento Ecológico. Tais resultados colocam em dúvida o real impacto de variáveis como Reciclagem ou Economia de Energia sobre o comportamento ecológico dos estudantes, ou ainda, o quanto a ação de reciclar ou economizar energia diz respeito a um comportamento ecológico consciente. Novos estudos precisam ser empreendidos sobre tais questões, no intuito de aprofundar o entendimento sobre o nível de influência das variáveis. Assim, isso deve ser investigado com maior atenção em futuros estudos.

Os achados trazem ainda contribuições práticas, e que podem ser utilizadas para tomada de decisão por gestores universitários e coordenadores de curso, no intuito de melhorar o comportamento ecológico dos estudantes. Entender em quais aspectos as IES devem atuar com foco na conscientização e/ou ação (economia de água, economia de energia, ativismo etc.) é um caminho adequado para tratar os problemas relacionados ao comportamento ecológico de seus estudantes.

Como limitações do estudo pode ser citada a amostra regionalizada, e por isso a impossibilidade de generalizar resultados, além da amostra regional utilizada. Para futuros estudos, sugere-se a ampliação da amostra, buscando universitários do curso de administração de diversas regiões e Estados, e com isso elaborar estudo comparativo.

\section{REFERÊNCIAS}

BABBIE, E. Métodos de pesquisa de survey. Belo Horizonte: Editora UFMG, 2003.

BARBIERI, J. C.; SILVA, D. Educação ambiental na formação do administrador. São Paulo: Cengage Learning, 2011.

BARBIERI, J. C. Educação Ambiental e a Gestão Ambiental nos cursos de graduação em Administração: objetivos, desafios e propostas. Revista de Administração Pública, v. 38, n. 6, p. 919-946, 2004.

BARKER, R. G. Explorations in ecological psychology. American Psychologist, v. 20, n. 1, p. 1-14, 1965.

BEURON, T. A.; SCHUCH JÚNIOR, V. F.; MADRUGA, L. R. R. G.; CARPES, A. M. Relações entre os valores pessoais e os comportamentos ecológicos no contexto da sustentabilidade. Revista Ibero-Americana de Ciências Ambientais, Aquidabã, v.3, n.2, jun./dez., 2012. 
BRAUS, J.; WOOD, D. Environment education in the schools: creating a program that works! Washington, DC: Peace Corps, 1993.

BUTZKE, I. C.; PEREIRA, G. R.; NOEBAUER, D. Sugestão de indicadores para avaliação do desempenho das atividades educativas do sistema de gestão ambiental - SGA da Universidade Regional de Blumenau - FURB. Revista Eletrônica do Mestrado em Educação Ambiental, edição especial, abr/maio/jun. 2001.

CARVALHO, M. I. C. Comportamentos de crianças pequenas em creches e arranjo espacial. Temas em Psicologia, v. 6. n. 2. p. 125-133. 1998.

CARVALHO, R. V.; DIAS, R. O desenvolvimento de uma cultura ambiental corporativa através da educação ambiental. Revista em Agronegócios e Meio Ambiente, v. 6, n. 3, p. 479-496, set./dez., 2013.

COIMBRA, D. B. Abordagens e limitações da educação ambiental no ensino superior: percepções a partir da disciplina de gestão ambiental nos cursos de graduação em administração na cidade de Fortaleza/CE. Tese (Doutorado em Educação). Universidade Federal do Ceará. Fortaleza. 2011.

CORRAL-VERDUGO, V.; PINHEIRO, J. Q. Condições para o estudo do comportamento pró-ambiental. Estudos de Psicologia, n. 4. p. 7-22. 1999.

CORRAR, L. J.; PAULO, E.; DIAS-FILHO, J. M. Análise multivariada: para cursos de administração, ciências contábeis e economia. São Paulo: Atlas, 2009.

DONATO, V. Logística verde: uma abordagem socioambiental. Rio de Janeiro: Ciência Moderna, 2008.

DOWBOR, L. Educação, tecnologia e desenvolvimento. In: BRUNO, L. Educação e trabalho no capitalismo. São Paulo: Atlas, 1996.

FERREIRA, D. D. M.; FERREIRA, L. F. O ensino de gestão ambiental nos cursos de administração de empresas nas IES (instituições de ensino superior) do estado de Santa Catarina: um estudo exploratório. In: IV CONGRESSO NACIONAL DE EXCELÊNCIA EM GESTÃO. Anais... Rio de Janeiro, 2008.

FREITAS, H. et al. O método de pesquisa survey. Revista de Administração, São Paulo, v. 35, n. 3, p. 105-112, jul./set., 2000.

HAIR, J. F. Jr.; BLACK, W. C.; BABIN, B. J.; ANDERSON, R. E.; TATHAM, R. L. Análise multivariada de dados. 6 ed. Porto Alegre: Bookman, 2009. 
José Milton de Sousa Filho, Danielle Batista Coimbra, Rafael Fernandes de Mesquita \& Roger Augusto Luna

HINES, J. M.; HUNGERFORD, H. R.; TOMERA, A. N. Analysis and synthesis of research on responsible environmental behavior: a meta-analysis. Journal of Environmental Education, n. 18, p. 1-8, 1987.

IBGE. Censo Demográfico de 2010. Fundação Instituto Brasileiro de Geografia e Estatística, dados referentes à cidade de Fortaleza - Ceará, fornecidos em meio eletrônico. Disponível em: 〈http://www.ibge.gov.br/cidadesat/painel/painel.php?codmun=230440> Acesso em 30 maio, 2013.

JACOBI, P. Educação ambiental, cidadania e sustentabilidade. Cadernos de Pesquisa, n. 118, p. 189-205, mar. 2003.

KRUGLIANSKAS, I. Ensino da gestão ambiental em escolas de administração de empresas: a experiência da FEA/USP. In: Encontro Nacional de Gestão Empresarial e Meio Ambiente. Anais... São Paulo: FEA/USP, EAESP/FGV, 1993.

KRUGLIANSKAS, I. Educação para a Gestão Ambiental: a cidadania no enfrentamento político dos conflitos socioambientais. In: LOUREIRO, C.; LAYRARGUES, P.; CASTRO, R. de (Orgs.). Sociedade e meio ambiente: a educação ambiental em debate. São Paulo: Cortez, 2002.

LEDESMA, R. D.; VALERO-MORA, P. Determining the number of factors to retain in EFA: an easy-to-use computer program for carrying out parallel analysis. Practical Assessment, Research \& Evaluation, v. 12, n. 2, p. 1-11, 2007.

LINS, S. L. B.; CAVALCANTI, C. M.; FARIA, R. C. P. Valores humanos e comportamento ecológico de universitários brasileiros e portugueses. Revista EDUCAMAZÔNIA, v. 1, n. 6, p. 42-74, jan./jun., 2011.

LOURES, R. C. R. Sustentabilidade XXI: educar e inovar sob uma nova consciência. São Paulo: Editora Gente, 2009.

MAY, T. Surveys sociais: do desenho à análise. In: MAY, T. Pesquisa social: questões, métodos e processos. Porto Alegre: Artmed, 2004.

MEADOWS, D. et al. Os limites do crescimento. São Paulo: Perspectiva, 1972.

MESQUITA, R. F.; SOUSA, L. R. M.; LIMA, F. F.; SILVA, G. O.; CARVALHO, M. L.; FERREIRA, A. K. A. Proposta metodológica e reflexões sobre o desenvolvimento sustentável e a educação ambiental no ensino médio. Revista Interdisciplinar, v. 7, n. 2, p. 165-172, 2014.

O'CONNOR, B. P. SPSS and SAS programs for determining the number of components using parallel analysis and Velicer's MAP test. Behavior Research Methods, Instrumentation, and Computers, 32, 396-402, 2000.

REAd | Porto Alegre - Edição 81 - N 2 - maio/agosto 2015 - p. 300-3019 
PATO, C. M. L.; TAMAYO, A. A Escala de comportamento ecológico: desenvolvimento e validação de um instrumento de medida. Estudos de Psicologia, v. 11, n. 3, p. 289-296, 2006.

PAULO, R. R. D.; FEROLLA, L. M. Ensaio Sobre a Educação Ambiental na Formação de Gestores. In: Encontro Nacional de Gestão Empresarial e Meio Ambiente, 2010. São Paulo. Anais... São Paulo: FEA/USP, 2010.

PINHEIRO, L. V. S.; MONTEIRO, D. L. C.; GUERRA, D. S.; PEÑALOZA, V. Transformando o discurso em prática: uma análise dos motivos e das preocupações que influenciam o comportamento pró-ambiental. Revista de Administração Mackenzie - RAM. v. 12, n. 3, ed especial, p. 83-113, maio/jun. 2011.

SILVA, H. H. M.; CAMPANARIO, M. A.; SOUZA, M. T. S. O isomorfismo na educação ambiental como tema transversal em programas de graduação em administração. Revista de Ciências da Administração, v. 15, n. 37, p. 170-186, dez. 2013.

SAUVÉ, L. Environmental education between modernity and postmodernity: searching for an integrating educational framework. Canadian Journal of Environmental Education, n. 4. p. 9-35, 1999.

L'éducation Relative à L'environnement: possibilities et contraintes. Educação e Pesquisa, São Paulo, v. 31, n.2, p. 317-322. 2005.

SIMÕES, R.; GIRALDI, J.; OLIVEIRA, S. Influência dos valores pessoais no comportamento verde do consumidor. Revista Portuguesa e Brasileira de Gestão, v. 11, n. 4, p. 26-37, 2012.

THOMAZ, C. Educação ambiental na formação inicial de professores. Dissertação (Mestrado em Educação) - Pontifícia Universidade Católica de Campinas, 2006.

UNITED NATIONS EDUCATIONAL SCIENTIF AND CULTURAL ORGANIZATION UNESCO; ORGANIZAÇÃO DAS NAÇÕES UNIDAS PARA A EDUCAÇÃO, CIÊNCIA E CULTURA. Tendências de la educación ambiental. Paris: Unesco, 1997. Disponível em www.unesco.org. Acessado em 18 nov 2013. 
José Milton de Sousa Filho, Danielle Batista Coimbra, Rafael Fernandes de Mesquita \& Roger Augusto Luna

\section{APÊNDICE A - Análise Fatorial}

Tabela 2 - Cargas fatoriais, comunalidades $\left(\mathrm{H}^{2}\right)$, percentual de variância explicada dos fatores com rotação varimax sobre os itens da Escala de Comportamento Ecológico (ECE).

\begin{tabular}{|c|c|c|c|c|c|c|c|}
\hline $\begin{array}{c}\text { Item da escala } \\
\end{array}$ & F1 & F2 & F3 & $\mathbf{F 4}$ & F5 & F6 & $\mathbf{H}^{2}$ \\
\hline $\begin{array}{l}\text { V1. Participo de atividades que cuidam do meio } \\
\text { ambiente. }\end{array}$ & & & & & & 680 &, 552 \\
\hline $\begin{array}{l}\text { V2. Participo de manifestações públicas para defender } \\
\text { o meio ambiente. }\end{array}$ & & & & & & ,703 &, 580 \\
\hline $\begin{array}{l}\text { V3. Faço trabalho voluntário para um grupo } \\
\text { ambiental. }\end{array}$ & & & & & & & ,453 \\
\hline $\begin{array}{l}\text { V4. Evito comprar produtos que são feitos de } \\
\text { plástico. }\end{array}$ & & & & & & &, 301 \\
\hline $\begin{array}{l}\text { V5. Evito comer alimentos que contenham produtos } \\
\text { químicos (conservantes ou agrotóxicos). }\end{array}$ & & & ,662 & & & & ,483 \\
\hline $\begin{array}{l}\text { V6. Mobilizo as pessoas nos cuidados necessários } \\
\text { para a conservação dos espaços públicos. }\end{array}$ & & & ,615 & & & &, 565 \\
\hline $\begin{array}{l}\text { V7. Falo sobre a importância do meio ambiente com } \\
\text { as pessoas. }\end{array}$ & & & ,619 & & & &, 592 \\
\hline $\begin{array}{l}\text { V8. Compro comida sem me preocupar se têm } \\
\text { conservantes ou agrotóxicos (inversa). }\end{array}$ & & & & & & & ,237 \\
\hline $\begin{array}{l}\text { V9. Evito usar produtos fabricados por uma empresa } \\
\text { quando sei que essa empresa está poluindo o meio } \\
\text { ambiente. }\end{array}$ & & & ,619 & & & & ,457 \\
\hline $\begin{array}{l}\text { V10. Quando estou em casa, deixo as luzes acesas em } \\
\text { ambientes que não são usados (inversa). }\end{array}$ & & & & & & & ,418 \\
\hline $\begin{array}{l}\text { V11. Enquanto escovo os dentes, deixo a torneira } \\
\text { aberta. }\end{array}$ & & & & & & & ,446 \\
\hline V12. Evito desperdício de energia (inversa). & & & & & & & ,458 \\
\hline $\begin{array}{l}\text { V13. Quando estou tomando banho, fecho a torneira } \\
\text { para me ensaboar. }\end{array}$ &, 832 & & & & & &, 723 \\
\hline $\begin{array}{l}\text { V14. Deixo a torneira aberta durante todo o tempo do } \\
\text { banho (inversa). }\end{array}$ & ,606 & & & & & &, 579 \\
\hline V15. Quando possível economizo água. & ,702 & & & & & & 605 \\
\hline $\begin{array}{l}\text { V16. Deixo a televisão ligada mesmo sem ninguém } \\
\text { assistindo a ela (inversa). }\end{array}$ & & & & ,624 & & & ,432 \\
\hline V17. Apago a luz quando saio de ambientes vazios. & & & & & & &, 459 \\
\hline $\begin{array}{l}\text { V18. Quando abro a geladeira já sei o que vou pegar, } \\
\text { evitando ficar com a porta aberta muito tempo, para } \\
\text { não gastar energia. }\end{array}$ & & & & & & & ,470 \\
\hline V19. Evito desperdício dos recursos naturais. & & & & & & & ,493 \\
\hline $\begin{array}{l}\text { V20. Quando tenho vontade de comer alguma coisa } \\
\text { que não sei o que é, abro a geladeira e fico olhando o } \\
\text { que tem dentro (inversa). }\end{array}$ & & & & ,603 & & & ,451 \\
\hline $\begin{array}{l}\text { V21. Evito ligar vários aparelhos elétricos ao mesmo } \\
\text { tempo nos horários de maior consumo de energia. }\end{array}$ & & & & & & & ,472 \\
\hline V22. Evito jogar papel no chão. & & 744 & & & & & ,642 \\
\hline $\begin{array}{l}\text { V23. Guardo o papel que não quero mais no bolso, } \\
\text { quando não encontro uma lixeira por perto. }\end{array}$ & & ,760 & & & & & ,613 \\
\hline $\begin{array}{l}\text { V24. Quando não encontro lixeira por perto, jogo } \\
\text { latas vazias no chão (inversa). }\end{array}$ & & & & & & & ,400 \\
\hline V25. Ajudo a manter as ruas limpas. & & ,701 & & & & & ,604 \\
\hline $\begin{array}{l}\text { V26. Colaboro com a preservação da cidade onde } \\
\text { vivo. }\end{array}$ & &, 654 & & & & &, 578 \\
\hline $\begin{array}{l}\text { V27. Providenciei uma lixeira específica para cada } \\
\text { tipo de lixo em minha casa. }\end{array}$ & & & & & ,789 & & ,670 \\
\hline V28. Separo o lixo conforme seu tipo. & & & & &, 787 & &, 712 \\
\hline
\end{tabular}


V29. Jogo todo tipo de lixo em qualquer lixeira

(inversa).

Variância explicada acumulada (\%)

Nota: nomes dos fatores:

F1- Economia de água

F2- Limpeza urbana

F3- Ativismo-consumo

F4- Economia de energia

F5- Reciclagem

F6- Ativismo

Fonte: Elaborada pelos autores com dados da pesquisa (2014).

\section{APÊNDICE B - Análise de Regressão}

Conforme mostra a Tabela 3, o erro-padrão da estimativa foi de 0,0488 , adequado para a estatística. A partir do teste de Durbin-Watson, pode-se observar que existe a possibilidade de autocorrelação serial (um dos pressupostos da análise de regressão, que trata da independência dos resíduos), pois o valor de 2,036 para este teste está acima do recomendado por Corrar et al. (2009), que afirma quando os valores adequados devem ser abaixo de 2,00. Contudo, não preocupa, já que o valor do teste Durbin-Watson ficou praticamente no limite permitido.

Tabela 3 - Sumário do modelo de regressão

\begin{tabular}{|c|c|c|c|c|c|c|c|c|c|c|}
\hline \multirow[t]{2}{*}{ Model } & \multirow[t]{2}{*}{$\mathrm{R}$} & \multirow{2}{*}{$\begin{array}{c}\mathrm{R} \\
\text { Square }\end{array}$} & \multirow{2}{*}{$\begin{array}{l}\text { Adjusted } \\
\text { R Square }\end{array}$} & \multirow{2}{*}{$\begin{array}{l}\text { Std. Error of } \\
\text { the Estimate }\end{array}$} & \multicolumn{5}{|c|}{ Change Statistics } & \multirow{2}{*}{$\begin{array}{l}\text { Durbin- } \\
\text { Watson }\end{array}$} \\
\hline & & & & & $\begin{array}{l}\text { R Square } \\
\text { Change }\end{array}$ & $\begin{array}{c}\mathrm{F} \\
\text { Change }\end{array}$ & df1 & df2 & $\begin{array}{c}\text { Sig. F } \\
\text { Change }\end{array}$ & \\
\hline 1 &, $996^{\mathrm{a}}$ & 992 & ,992 & ,04884 &, 992 & 9936,98 & 6 & 479 &, 000 & 2,036 \\
\hline
\end{tabular}

Fonte: Elaborada pelos autores com dados da pesquisa (2014).

A análise de regressão apresentou a soma dos quadrados no valor de 143,353, com resíduos no valor de 1,143. A soma dos quadrados é o resíduo quadrado caso fosse utilizada apenas a média da variável dependente Comportamento Ecológico para predição. Ao incluir as variáveis independentes na equação, esse resíduo caiu para 1,143, ou seja, melhorou o poder de predição do modelo. O teste ANOVA $(F=9936,98$, Sig < 0,001) com significância estatística atesta que o modelo é válido, pois se rejeita a hipótese de que o $\mathrm{R}^{2}$ é igual a zero. Tais resultados podem ser vistos na Tabela 4.

Tabela 4 - ANOVA

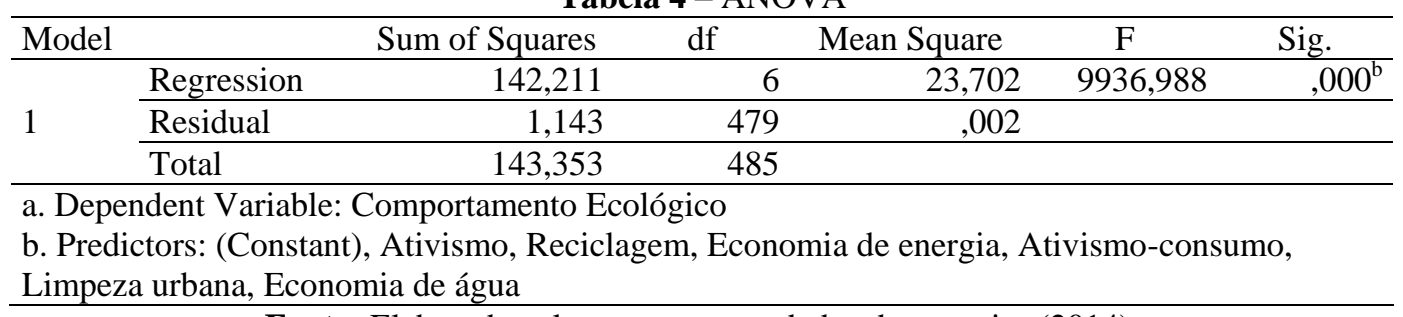

Fonte: Elaborada pelos autores com dados da pesquisa (2014).

Todos os coeficientes de regressão (B), coeficientes padronizados Beta e a significância estatística de cada variável podem ser observados na Tabela 5. A partir dos

REAd | Porto Alegre - Edição 81 - N 2 - maio/agosto 2015 - p. 300-3019 
José Milton de Sousa Filho, Danielle Batista Coimbra, Rafael Fernandes de Mesquita \& Roger Augusto Luna

resultados da análise de regressão, observa-se que todas as variáveis apresentaram significância estatística, assim, estas constituíram a seguinte equação de regressão:

$\mathrm{CE}=3,320+0,271 \mathrm{~F} 1+0,265 \mathrm{~F} 2+0,239 \mathrm{~F} 3+0,212 \mathrm{~F} 4+0,181 \mathrm{~F} 4+0,122 \mathrm{~F} 6$

Tabela 5 - Coeficientes análise de regressão

\begin{tabular}{|c|c|c|c|c|c|c|c|c|}
\hline \multirow{2}{*}{\multicolumn{2}{|c|}{ Model }} & \multicolumn{2}{|c|}{$\begin{array}{l}\text { Unstandardized } \\
\text { Coefficients }\end{array}$} & \multirow{2}{*}{$\begin{array}{c}\text { Standardized } \\
\text { Coefficients } \\
\text { Beta }\end{array}$} & \multirow[t]{2}{*}{$\mathrm{t}$} & \multirow[t]{2}{*}{ Sig. } & \multicolumn{2}{|c|}{$\begin{array}{c}\text { Collinearity } \\
\text { Statistics }\end{array}$} \\
\hline & & $\mathrm{B}$ & Std. Error & & & & Tolerance & VIF \\
\hline \multirow{7}{*}{1} & (Constant) & 3,320 & ,002 & & 1498,494 & ,000 & & \\
\hline & Economia de água &, 271 & ,002 & ,498 & 122,010 &, 000 & 1,000 & 1,000 \\
\hline & Limpeza urbana &, 265 & ,002 & ,488 & 119,716 &, 000 & 1,000 & 1,000 \\
\hline & Ativismo-consumo & ,239 & ,002 & ,439 & 107,658 & ,000 & 1,000 & 1,000 \\
\hline & Economia de energia & ,212 &, 002 & ,391 & 95,820 &, 000 & 1,000 & 1,000 \\
\hline & Reciclagem & ,181 & ,002 & ,332 & 81,413 &, 000 & 1,000 & 1,000 \\
\hline & Ativismo &, 122 & ,002 & 224 & 54,805 &, 000 & 1,000 & 1,000 \\
\hline
\end{tabular}

a. Dependent Variable: Comportamento Ecológico

Fonte: Elaborada pelos autores com dados da pesquisa (2014).

A ausência de multicolinearidade pode ser comprovada pela estatística de colinearidade, especificamente pelo teste VIF. Conforme pode-se constatar na última coluna da Tabela 5, o VIF de todas as variáveis foi 1,000. Hair et al. (2009) recomendam que o VIF adequado deve ficar abaixo de 10; desta forma, percebe-se que não existe problema de multicolinearidade no modelo.

Por fim, para verificar a normalidade dos resíduos, procedeu-se com o teste nãoparamétrico Kolmogorov-Smirnov (KS). Este teste examina se a série de dados está conforme a distribuição esperada, nesse caso, a distribuição normal. A hipótese nula é que a distribuição da série de dados é normal, desta forma, espera-se que a significância do teste seja maior que 0,000, para que se aceite a hipótese nula. Ao realizar o KS, constatou-se que a amostra de resíduos padronizados apresenta normalidade, já que a significância do teste foi 0,217 , e desta forma, não se pode rejeitar a hipótese nula. $\mathrm{O}$ resultado do teste pode ser visto na Tabela 6 .

Tabela 6 - Teste Kolmogorov-Smirnov

\begin{tabular}{|c|c|c|}
\hline & & $\begin{array}{c}\text { Standardized } \\
\text { Residual } \\
\end{array}$ \\
\hline $\mathrm{N}$ & & 486 \\
\hline \multirow{2}{*}{ Normal Parameters ${ }^{\mathrm{a}, \mathrm{b}}$} & Mean & 0E-7 \\
\hline & Std. Deviation & ,99379518 \\
\hline \multirow{3}{*}{ Most Extreme Differences } & Absolute &, 048 \\
\hline & Positive & 032 \\
\hline & Negative &,- 048 \\
\hline \multicolumn{2}{|l|}{ Kolmogorov-Smirnov Z } & 1,053 \\
\hline \multicolumn{2}{|l|}{ Asymp. Sig. (2-tailed) } & ,217 \\
\hline \multicolumn{2}{|l|}{$\begin{array}{l}\text { a. Test distribution is Normal. } \\
\text { b. Calculated from data. }\end{array}$} & \\
\hline
\end{tabular}

Desta forma, os pressupostos básicos da regressão (autocorrelação serial, multicolinearidade, normalidade dos resíduos) foram testados, e com isso pôde-se confirmar a adequação do modelo e de seus resultados. 